\title{
In Vitro Application of Sonodynamic Antimicrobial Chemotherapy as a Sonobactericidal Therapeutic Approach for Bacterial Infections: A Systematic Review and Meta-analysis
}

\author{
Maryam Pourhajibagher ${ }^{1}{ }^{\mathbb{D}}$, Abbas Bahador $^{2 *(\mathbb{D}}$ \\ ${ }^{1}$ Dental Research Center, Dentistry Research Institute, Tehran University of Medical Sciences, Tehran, Iran \\ ${ }^{2}$ Oral Microbiology Laboratory, Department of Medical Microbiology, School of Medicine, Tehran University of Medical \\ Sciences, Tehran, Iran
}

\section{*Correspondence to Abbas Bahador, Ph.D; Professor in Microbiology, Oral Microbiology Laboratory, Department of Microbiology, Tehran University of Medical Sciences, Tehran, Iran. Telefax: (+98) 21-88955810; Email: abahador@sina.tums.ac.ir}

Published online December 30, 2020

\begin{abstract}
Introduction: This study aimed to perform a systematic review of the literature followed by a meta-analysis about the efficacy of sonodynamic antimicrobial chemotherapy (SACT) in bacterial infections.

Methods: According to the PICOS (population, intervention, comparison and outcome) recommendations and PRISMA guidelines, an electronic search was conducted in PubMed, SCOPUS, Embase, and Cochrane Library based on the MeSH terms. All analyses were conducted using Biostat's Comprehensive Meta-Analysis version 2.0. The inter-study heterogeneity and publication bias assessments were carried out on the studies using $l^{2}$ and the Egger's regression test. Results: Initially, 126 articles were identified in the electronic search, and 14 studies remained after analysis and exclusion of the duplicated studies and eligibility criteria. All results from the included studies displayed a significant reduction of microorganisms. The meta-analysis demonstrated a significant reduction in the bacterial load in all analyses $(0.944 \%$ [95\% Cl, $0.901-0.969 \%$; $P=0.000]$ ). Also, there was a low risk of bias for microbial load reduction without the evidence of publication bias.

Conclusion: The results highlight that there is scientific evidence emphasizing the effectiveness of SACT in reducing the count of microorganisms in bacterial infections.

Keywords: Systematic review; Meta-analysis; Sonodynamic antimicrobial chemotherapy; Microbial infections.
\end{abstract}

\section{Introduction}

Sonodynamic antimicrobial chemotherapy (SACT) is an interesting ultrasound therapeutic modality for treating malignancies such as cancer cells and killing the microorganisms. ${ }^{1-4}$ SACT is a kind of therapeutic modality which uses the sensitization of the target site with a non-toxic sonosensitizer, the relatively low-intensity ultrasound, and molecular oxygen which may produce the microbubbles through the acoustic cavitation process during the interactions between the ultrasound wave and target cells (Figure 1). ${ }^{5}$ During SACT, the reactive oxygen species is produced that is toxic to target cells similar to other approaches such as antimicrobial photodynamic therapy (aPDT). ${ }^{2,3}$ The main advantage of SACT over aPDT is the increased penetration of ultrasound to the target site compared to light. ${ }^{6}$

Interestingly, many of the sonosensitizers used in SACTbased studies were used as photosensitizers. ${ }^{7}$ The most distinguished mechanical effect of ultrasound on tissue is acoustic cavitation which leads to the formation of the bubbles with gas and/or vapor-filled cavities in a medium exposed to an ultrasound process. ${ }^{8}$ Ultrasound not only can enhance the bioavailability of sonosensitizer, but can also modify the chemical properties of sonosensitizer. ${ }^{9}$ Major uses of ultrasound are listed in Figure 2.

Although the effects of SACT on the treatment of different cancers have been systematically reviewed, the efficacy of SACT in the elimination of bacterial infections may be critical in adopting novel strategies for the microbial treatment. To the best of our knowledge, there have been no previous systematic reviews and meta-analyses analytically addressing the question of whether SACT leads to the removal of bacterial infections. Thus, this systematic review and meta-analysis aimed to investigate the in vitro application of SACT as a sonobactericidal therapeutic approach for bacterial infections.

Please cite this article as follows: Pourhajibagher M, Bahador A. In Vitro Application of Sonodynamic Antimicrobial chemotherapy as a sonobactericidal therapeutic approach for bacterial infections: a systematic review and meta-analysis. J Lasers Med Sci. 2020;11(suppl 1):S1-S7. doi:10.34172/jlms.2020.S1. 


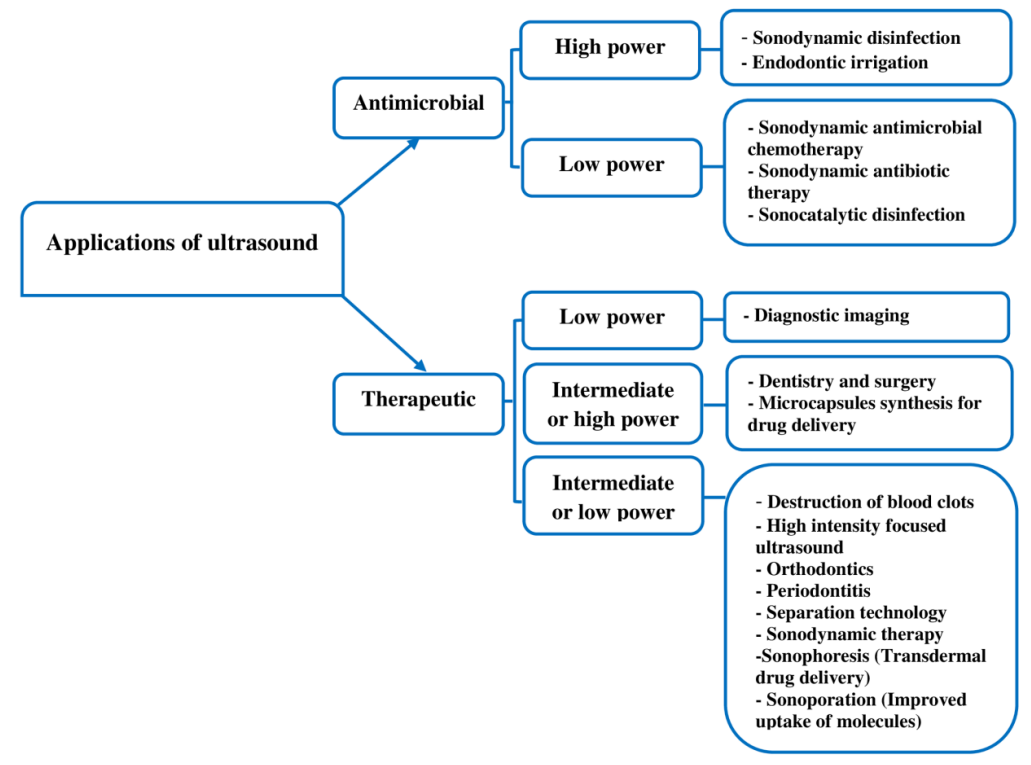

Figure 1. Applications of Ultrasound.

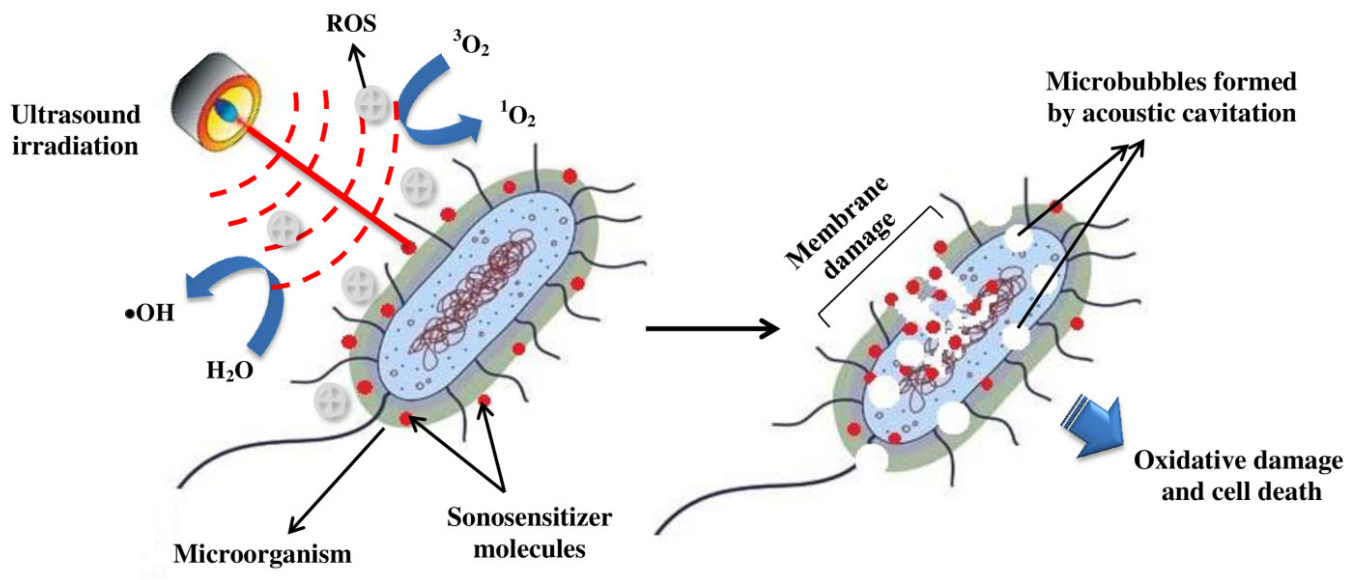

Figure 2. Mechanisms of Sonodynamic Antimicrobial Chemotherapy Function.

\section{Materials and Methods \\ Focused Question}

According to the Preferred Reporting Items for Systematic Review and Meta-Analyses (PRISMA) guideline, ${ }^{10}$ the following focused question has been utilized to identify the application of SACT: "Can SACT be used to eradicate the bacterial infections?"

\section{Sources of Information and Search Strategies}

For all related studies, PubMed, SCOPUS, Embase, and Cochrane Library were searched from January 1, 2005 to January 1, 2020 using the following keywords based on the medical subject heading (MeSH) terms, including "sonodynamic therapy", "sonodynamic chemotherapy", "sonodynamic antimicrobial chemotherapy", "bacteria", "microbe" alone or in combination with "OR" and/or "AND" in the English language.

\section{Eligibility Criteria}

Articles were included according to the population, intervention, comparison and outcome (PICOS) for the focused objective:

Population (P): Microorganisms

Intervention (I): Treatment of bacterial infections with SACT/SDT

Comparison (C): Before and after SACT/SDT

Outcome (O): Load and/or count of microorganisms Study (S): In vitro studies

All original research papers and short reports published in the English language regarding the microbial load before and after the SACT application were included in the study. Duplicated articles, review articles, letters to the editor, short commentaries, dissertations, and reported studies that were not available in the English language were excluded. 


\section{Study Selection and Data Extraction}

After a primary screening of the articles, two reviewers independently ( $\mathrm{AB}$ and $\mathrm{MP}$ ) assessed the final eligibility and inclusion criteria for the downloaded papers and the results were checked by MP. The information from the accepted studies was tabulated, including the name of the first author, the publication date, and the type and total number of microorganisms. Moreover, the SACT parameters were evaluated by the type of sonosensitizer, the concentration of sonosensitizer, ultrasound frequency $(\mathrm{MHz})$, power density $\left(\mathrm{W} / \mathrm{cm}^{2}\right)$, the duration of irradiation, and the treatment outcome.

\section{Statistical Analysis}

In the present study, all statistical analyses were performed using Biostat's Comprehensive Meta-Analysis version 2.0 (Englewood, NJ, USA). The heterogeneity comparison was checked using both chi-square (Cochran's Q) and $I^{2}$ tests. A random-effect model (for high heterogeneity; $I^{2}$ $>50 \%$ ) and a fixed-effect model (for low heterogeneity; $\left.I^{2}<50 \%\right)$ were used depending on the heterogeneity test. In addition, publication bias was assessed statistically by using Begg's and Egger's tests and 95\% confidence interval (CI) was measured for each study.

\section{Results}

\section{Study Characteristics}

Figure 3 summarizes the study selection process according to the PRISMA. A total of 126 articles were found in the initial search and 83 duplicates were excluded after the first screening. After excluding non-eligible papers, 20 articles had eligibility to be considered for full-text reading. Of these 20 studies, 4 studies were further excluded and in

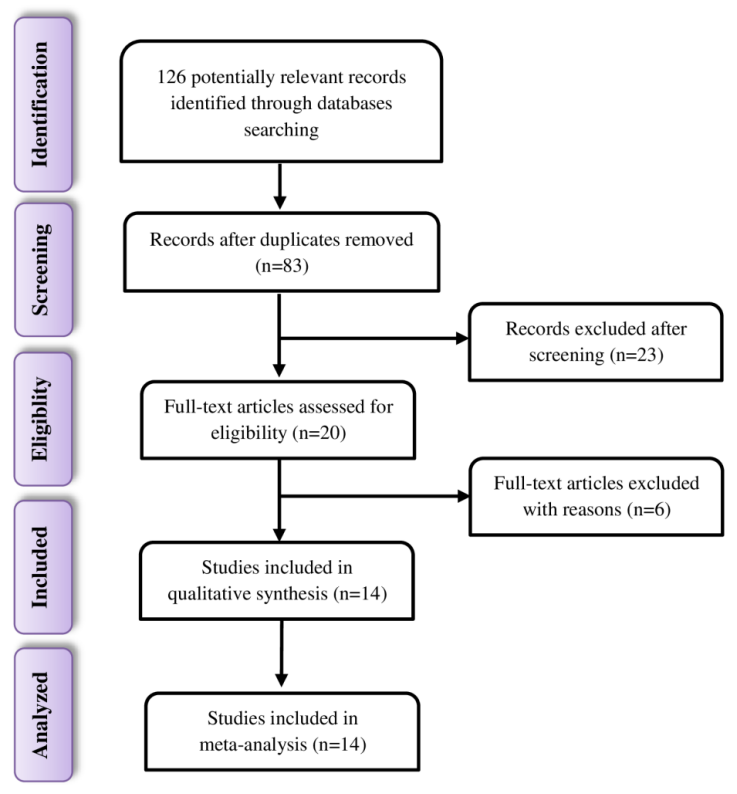

Figure 3. Flow Diagram of the Study Design Process Based on the PRISMA Guidelines.

\begin{tabular}{|c|c|c|c|c|c|c|c|}
\hline Study & 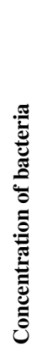 & 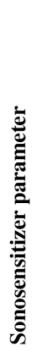 & 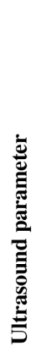 & 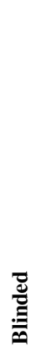 & 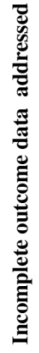 & 苛 & 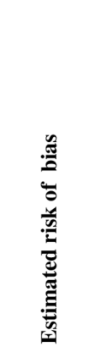 \\
\hline Ensing et al. & 0 & - & 0 & 0 & 0 & 4 & Moderate \\
\hline Dadjour et al. & - & - & - & - & - & 5 & Low \\
\hline Tachibana et al. & 0 & - & 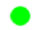 & 6 & - & 5 & Low \\
\hline Drakopoulou et al. & - & - & - & 0 & - & 5 & Low \\
\hline Rahman et al. & - & - & - & ○ & - & 4 & Moderate \\
\hline Liu et al. & 0 & - & - & 0 & 0 & 5 & Low \\
\hline Nakonechny et al. & 9 & - & 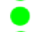 & 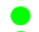 & - & 5 & Low \\
\hline Zhuang et al. & 0 & - & 0 & 0 & - & 5 & Low \\
\hline Wang et al. & - & ? & ? & 0 & 0 & 5 & Low \\
\hline Wang et al. & 0 & 0 & 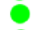 & 0 & 0 & 5 & Low \\
\hline Wang et al. & 0 & - & - & 0 & 0 & 5 & Low \\
\hline Costley et al. & - & - & - & - & - & 5 & Low \\
\hline Xu et al. & 0 & e & 0 & 0 & 6 & 4 & Moderate \\
\hline Pang et al. & 0 & - & 0 & 0 & 0 & 5 & Low \\
\hline
\end{tabular}

Figure 4. Quality Assessment of the Selected Studies (the CONSORT Tool for Assessing the Risk of Bias).

the final stage of screening, 14 studies ${ }^{11-24}$ were included in the current systematic review and meta-analysis. The main characteristics of the included studies are described in Table 1.

\section{Risk of Bias Assessment}

Based on the results obtained with the recommendations of the CONSORT statement, ${ }^{25}$ the included records had a low risk of bias. The quality assessment for each included study is provided in Figure 4. The statistical analysis methodology revealed that two of the studies, Ensing et $\mathrm{al}^{11}$ and Rahman et $\mathrm{al}{ }^{15}$ did not report the concentration of used sonosensitizers. Overall, there was no attrition bias due to missing data, thereby increasing the strength of scientific evidence of the current systematic review and meta-analysis study.

\section{Sonosensitizer Parameters of the Included Studies}

The sonosensitizers included antibiotic (i.e. gentamycin, ciprofloxacin/levofloxacin), titanium dioxide $\left(\mathrm{TiO}_{2}\right)$, bubble liposome, rose bengal (RB), rose bengalantimicrobial peptide conjugate (RB-C $\left[\mathrm{KLAKLAK}_{2}\right.$ ), curcumin (Cur), hypocrellin B, encapsulating purpurin 18 into maltohexaose-decorated cholesterol nanoliposomes (MLP18), and hematoporphyrin monomethyl ester (HMME) (Table 1). Dadjour et al, ${ }^{12}$ Drakopoulou et al, ${ }^{14}$ and Rahman et al. ${ }^{15}$ used $\mathrm{TiO}_{2}$ as a sonosensitizer in their studies. HMME was used as a sonosensitizer in studies by Zhuang et $\mathrm{al}^{18}$ and $\mathrm{Xu}$ et $\mathrm{al}^{23}$ Gentamycin and ciprofloxacin/levofloxacin were used by Ensing et $\mathrm{al}^{11}$ and Liu et $\mathrm{l}^{16}$ respectively. Nakonochny et $\mathrm{al}^{17}$ used $\mathrm{RB}$, while Costley et $\mathrm{a}^{22}$ used RB-C(KLAKLAK) ${ }_{2}$ in their study. Cur was used as a sonosensitizer in studies by Wang et $\mathrm{al},{ }^{19,20}$ whereas Tachibana et $\mathrm{al},{ }^{13}$ Wang et $\mathrm{al}^{21}$ and Pang 
Table 1. Antimicrobial Activity Induced by SACT on Microorganisms

\begin{tabular}{|c|c|c|c|c|c|c|c|c|c|}
\hline \multirow[b]{2}{*}{ Author, Year } & \multirow[b]{2}{*}{ Microorganism } & \multirow[b]{2}{*}{ Sonosensitizer } & \multirow[b]{2}{*}{ Concentration } & \multirow{2}{*}{$\begin{array}{l}\text { Ultrasound } \\
\text { Frequency } \\
(\mathrm{MHz})\end{array}$} & \multicolumn{2}{|c|}{$\begin{array}{l}\text { Irradiation } \\
\text { Conditions }\end{array}$} & \multicolumn{2}{|c|}{ Outcomes } & \multirow[b]{2}{*}{ Ref } \\
\hline & & & & & $\begin{array}{c}\text { Power } \\
\text { Density } \\
\left(\mathrm{W} / \mathrm{cm}^{2}\right)\end{array}$ & Time & $\begin{array}{c}\text { Initial } \\
\text { Load } \\
(\mathrm{CFU} / \mathrm{mL})\end{array}$ & $\begin{array}{l}\text { Microbial } \\
\text { Load } \\
\text { Reduction }\end{array}$ & \\
\hline Ensing et al, 2005 & Escherichia coli & Gentamycin & $N^{a}$ & $0.028-0.048$ & 0.5 & $48 \mathrm{~h}$ & $10^{9}$ & $2 \log$ & 11 \\
\hline Adjourn et al, 2006 & Legionella spp. & $\mathrm{TiO}_{2}^{\mathrm{b}}$ & $1 \mathrm{mg} / \mathrm{mL}$ & 0.036 & 300 & $1 \mathrm{~h}$ & $10^{3}$ & $2 \log$ & 12 \\
\hline Tachibana et al, 2008 & Chlamydia trachomatis & Bubble liposome & $1 \mathrm{mg} / \mathrm{mL}$ & 1 & 0.15 & $20 \mathrm{~s}$ & $10^{4}$ & $66 \%$ & 13 \\
\hline \multirow{5}{*}{$\begin{array}{l}\text { Drakopoulou et al, } \\
2009\end{array}$} & Pseudomonas spp. & \multirow{5}{*}{$\mathrm{TiO}_{2}$} & \multirow{5}{*}{$5 \mathrm{mg} / \mathrm{mL}$} & \multirow{5}{*}{0.024} & \multirow{5}{*}{300} & \multirow{5}{*}{$1 \mathrm{~h}$} & $10^{7}$ & $99.9 \%$ & \multirow{5}{*}{14} \\
\hline & Total coliforms & & & & & & $10^{6}$ & $99.9 \%$ & \\
\hline & Faecal coliforms & & & & & & $10^{5}$ & $99.9 \%$ & \\
\hline & Faecal streptococci & & & & & & $10^{5}$ & $72.8 \%$ & \\
\hline & Clostridium perfringens & & & & & & $10^{4}$ & $87.1 \%$ & \\
\hline Rahman et al, 2010 & Escherichia coli & $\mathrm{TiO}_{2}$ & ND & 0.036 & 0.28 & $70 \mathrm{~min}$ & $10^{8}$ & $1 \log$ & 15 \\
\hline Liu et al, 2011 & Escherichia coli & $\begin{array}{l}\text { Ciprofloxacin/ } \\
\text { levofloxacin }\end{array}$ & $0.01 \mathrm{mg} / \mathrm{mL}$ & 0.04 & 1 & $45 \mathrm{~min}$ & $10^{4}$ & $2 \log$ & 16 \\
\hline Nakonechny et al, & Staphylococcus aureus & \multirow{2}{*}{$\mathrm{RB}^{\mathrm{c}}$} & \multirow{2}{*}{$5 \mu \mathrm{M}$} & \multirow{2}{*}{0.028} & \multirow{2}{*}{0.84} & \multirow{2}{*}{$1 \mathrm{~h}$} & \multirow{2}{*}{$10^{9}$} & $2.1 \log$ & \\
\hline 2013 & Escherichia coli & & & & & & & $3.1 \log$ & 17 \\
\hline Zhuang et al, 2014 & Staphylococcus aureus & $\mathrm{HMME}^{\mathrm{d}}$ & $50 \mu \mathrm{g} / \mathrm{mL}$ & 1 & 6.0 & $30 \mathrm{~min}$ & $10^{8}$ & $95 \%$ & 18 \\
\hline Wang et al, 2014 & MRSA & Cure & $40 \mu \mathrm{M}$ & 1 & 1.56 & $5 \min$ & $10^{7}$ & $5 \log$ & 19 \\
\hline Wang et al, 2015 & $\begin{array}{l}\text { Bacillus cereus } \\
\text { Escherichia coli }\end{array}$ & Cur & $\begin{array}{c}2 \mu \mathrm{M} \\
40 \mu \mathrm{M}\end{array}$ & 1 & 1.56 & $\begin{array}{l}3 \min \\
5 \min \end{array}$ & $10^{6}$ & $\begin{array}{c}5.6 \log \\
2 \log \end{array}$ & 20 \\
\hline Wang et al, 2016 & MRSA & Hypocrellin B & $40 \mu \mathrm{M}$ & 1 & 1.38 & $5 \min$ & $10^{6}$ & $5 \log$ & 21 \\
\hline Costley et al, 2017 & $\begin{array}{l}\text { Staphylococcus aureus } \\
\text { Pseudomonas aeruginosa }\end{array}$ & RB-C $(\text { KLAKLAK })_{2}{ }^{f}$ & $10 \mu \mathrm{M}$ & 1 & 3.0 & $\begin{array}{l}10 \min \\
6 \min \end{array}$ & $10^{8}$ & $\begin{array}{l}5 \log \\
7 \log \end{array}$ & 22 \\
\hline Xu et al, 2017 & $\begin{array}{l}\text { MRSA } \\
\text { Escherichia coli }\end{array}$ & HMME & $125 \mu \mathrm{g} / \mathrm{mL}$ & ND & 2.0 & $10 \mathrm{~min}$ & $10^{9}$ & $\begin{array}{l}70 \% \\
70 \%\end{array}$ & 23 \\
\hline Pang et al, 2019 & $\begin{array}{l}\text { MRSA } \\
\text { Escherichia coli }\end{array}$ & MLP18 & $20 \mu \mathrm{M}$ & 1 & 0.97 & $5 \min$ & $10^{6}$ & $\begin{array}{l}98 \% \\
75 \%\end{array}$ & 24 \\
\hline
\end{tabular}

Abbreviation: MRSA, Methicillin-resistant Staphylococcus aureus.

a: Not-determined, b: titanium dioxide (TiO2), c: rose bengal (RB), d: hematoporphyrin monomethyl este, e: curcumin, f: rose bengal- antimicrobial peptide conjugate (RB-C[KLAKLAK]2), g: encapsulating purpurin 18 into maltohexaose-decorated cholesterol nanoliposomes.

et $\mathrm{al}^{24}$ used bubble liposome, hypocrellin B, and MLP18 respectively. Different concentrations of sonosensitizers were reported in these studies (Table 1).

\section{Ultrasound Parameters of the Included Studies}

The ultrasound parameters collected from the 14 selected studies are summarized in Table 1. Most of the studies ${ }^{13,18-22,24}$ used the ultrasound waves at a frequency of $1 \mathrm{MHz}$. In the other studies, ${ }^{11,12,14-17}$ ultrasound frequencies less than 0.05 were used and $\mathrm{Xu}$ et $\mathrm{al}^{23} \mathrm{did}$ not describe the ultrasound frequency. The power density ranged between 0.28 and $300 \mathrm{~W} / \mathrm{cm}^{2}$ and different times of ultrasonic irradiation were used in the included studies so that the minimum and maximum ultrasonic irradiation times were 20 seconds ${ }^{13}$ and 48 hours ${ }^{11}$ respectively.

\section{Microbiological Outcomes}

The type of investigated microorganisms has been reported in all studies (Table 1). As the studies show, there was a significant difference in the reduction of the microbial load following SACT. By contrast to gramnegative bacteria, the sonobactericidal effects of most sonosensitizers in the included studies on gram-positive bacteria were statistically higher, which may be due to structural differences in the cell wall composition. However, there is a difference in the study by Costley et al. ${ }^{22}$ Their results revealed that SACT using $10 \mu \mathrm{M}$ RB-C (KLAKLAK) ${ }_{2}$ reduced the number of $P$. aeruginosa by $7 \mathrm{log}$, and this reduction was also $2 \log$ greater than Staphylococcus aureus. The main reason is related to the interaction between the positively charged C(KLAKLAK) and the negatively charged Pseudomonas aeruginosa cell wall. $^{22}$

\section{Meta-analysis}

As shown by the random-effects model ( $Q$ value = 143.377; df $(Q)=22$; and $\left.I^{2}=84.656\right)$, the success rate of SACT in the eradication of bacterial infections was estimated to be $0.944 \%$ (95\% CI, 0.901-0.969\%; $P=0.000$ ). The Forest plots of the current study (Figure 5) demonstrated that all of the meta-analysis data presented a significant difference before and after SACT. Based on the Funnel plot of meta-analysis in Figure 6, there was no significant publication bias. According to the results, the estimated ranks of the correlation coefficients of Begg and 


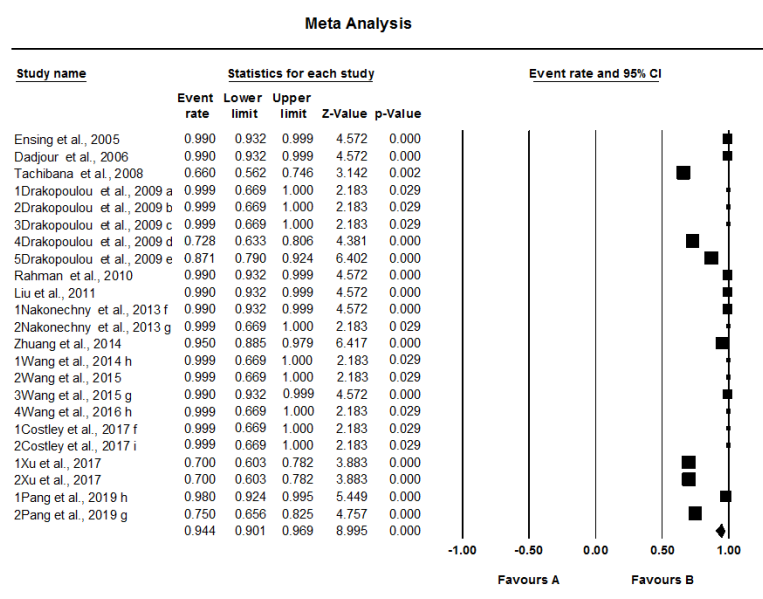

Figure 5. Forest Plots of the Meta-analysis of SACT Application to Eradicate the Bacterial Infections.

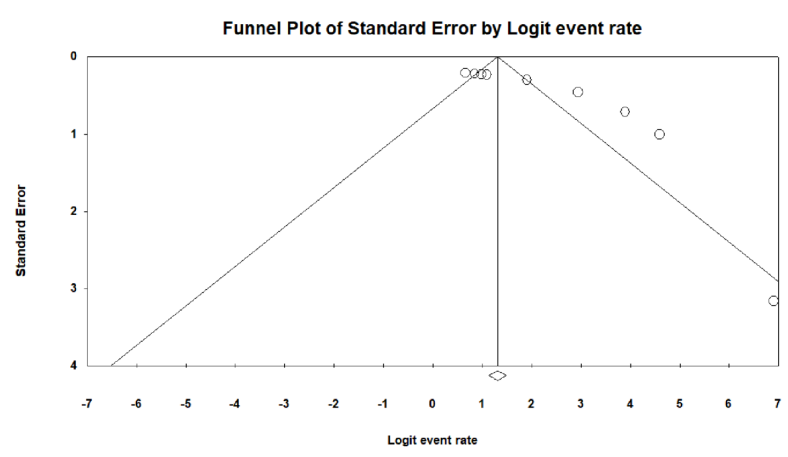

Figure 6. Funnel Plots of the Meta-analysis to Investigate Publication Bias.

Mazumdar rank and Egger's regression intercept were 0.34 and 0.00 respectively.

\section{Main Outcome of the Studies}

The risk of bias of the included articles in this study was considered low. In addition, the most accurate studies are plotted in the upper part of the Funnel plot, evincing the low risk of bias (Figure 6). Overall, the included pooled in vitro studies show that SACT can be effective in the elimination of microorganisms.

\section{Discussion}

Previous studies have mentioned satisfactory results with SACT in inhibiting microorganisms due to its strong penetrating power through a sonochemical process. ${ }^{1-4}$

SACT is analogous to aPDT except that drug activation is achieved through ultrasound instead of light. Furthermore, the photosensitizer as a photosensitizing agent in aPDT is replaced by the sonosensitizer as a sonosensitizing agent in SACT. ${ }^{26}$ The stimulus in SACT is non-thermal and recognized as being a nontoxic approach. In addition, SACT minimizes the side effects and maximizes the on-target responses. Another advantage of this method is that unlike light in aPDT, ultrasound in the SACT process can be focused deeply within the target site to a single discrete point in three dimensions. ${ }^{27}$

During SACT, the synergistic interaction of ultrasound with $1.0-2.0 \mathrm{MHz}$ at an intensity of $0.5-3.0 \mathrm{~W} / \mathrm{cm}^{2}$ and sonosensitizers produce cavitation in the target cells. ${ }^{28}$ Nucleation, bubble growth, and the implosive collapse of gas-filled bubbles are the results of the cavitation process. ${ }^{16,19,20,29,30}$ Following the activation of the sonochemical reactor, an extreme temperature up to 5000 $\mathrm{K}$ and pressure of $500 \mathrm{~Pa}$ are produced ${ }^{4}$; the sonosensitizer attaches to the surface of target cells, and it will be activated when it is exposed to the ultrasound. ${ }^{27}$ After that, released energy can be transferred to the oxygen and generate reactive oxygen species (ROS). This sonosensitizerderived ROS then reacts with dissolved oxygen to form other ROS which subsequently mediates cellular toxicity directly (Figure 2). ${ }^{2}$ Experimental evidence indicates that sonochemical effects are mediated through different ways including:

- Hydrodynamic stress

- Hydroxyl radicals $(\cdot \mathrm{OH})$

- $\quad$ Singlet molecular oxygen $\left({ }^{1} \mathrm{O}_{2}\right)$

- Other free radicals

According to Tachibana et al, ${ }^{13}$ cavitation has been classified into non-inertial (oscillating bubbles) and inertial (collapsing bubbles) forms that are capable to produce mechanical effects on the cell membranes. It has been suggested that the non-inertial cavitation, oftentimes termed as stable cavitation, describes a cyclic and nonlinear expansion and contraction of the bubbles due to the generated rapid flow of liquid around the bubbles, whereas the violent collapse of the bubbles is produced in inertial cavitation. ${ }^{13}$ The shear stresses on membranes, an increase in the permeability of membranes (sonoporation), as well as induced sonochemical reactions due to ROS generation are related to the non-inertial cavitation, and the dramatic changes in the morphology of the cell membrane are induced via inertial cavitation. ${ }^{31}$ Sonochemical reactions can occur in different regions such as the interior of the collapsing bubbles, the turbulent interface between the bubbles, and the bulk solvent. ${ }^{13}$

The studies in Table 1 demonstrated the efficacy of SACT with low-intensity ultrasound and different sonosensitizers in reducing the microbial load. All included studies have demonstrated the susceptibility of bacterial infections to SACT, suggesting that this therapy may be useful as a sonobactericidal therapeutic approach for control of bacterial infections.

Of the 14 studies, $\mathrm{TiO}_{2}$ was used as the sonosensitizer in 3 studies. Dadjour et al, ${ }^{12}$ Drakopoulou et $\mathrm{al},{ }^{14}$ and Rahman et $\mathrm{al}^{15}$ evaluated the sonodynamic antimicrobial effects of $\mathrm{TiO}_{2}$ on gram-positive and gram-negative bacteria. As seen in Table 1, their results suggested that 
$\mathrm{TiO}_{2}$ mediated-SACT has a good antibacterial effect on Legionella spp., Pseudomonas spp., total coliforms, faecal coliforms, C. perfringens, and E. coli. Also, among the evaluated articles, the most common microorganisms that were evaluated were E. coli, ${ }^{11,14-17,20,23,24}$ methicillinresistant S. aureus (MRSA), ${ }^{19,21,23,24}$ and S. aureus. ${ }^{17,18,22}$

It is interesting to note that all of these sonosensitizers respond to ultrasound at relatively low frequencies ranging from 0.028 to $1 \mathrm{MHz}$. Further, it should be noted that many of these sonosensitizers can be activated using an ultrasound intensity/power density ranging from 0.15 to $300 \mathrm{~W} / \mathrm{cm}^{2}$ (intensity spatial average-temporal average).

The results of the present study are in agreement with previous reviews that found a positive effect of SACT; however, those systematic reviews did not include the meta-analysis evaluation; therefore, definitive conclusions cannot be drawn. Additionally, limited clinical information remains on the use of SACT against the microorganisms.

\section{Conclusion}

The current systematic review and meta-analysis showed that SACT is a promising application because it offers a proper alternative to systemic antibiotic administration and can decrease the treatment time, thereby offering a new weapon in the fight against the bacterial infections.

\section{Ethical Consideration}

Not applicable.

\section{Conflict of Interests}

The authors declare that there are no conflicts of interest regarding the publication of this paper.

\section{Acknowledgments}

This research was supported by the Dental Research Center, Dentistry Research Institute, Tehran University of Medical Science, Tehran University of Medical Sciences \& Health Services grant No. 98-2-134-43562.

\section{References}

1. Serpe L, Giuntini F. Sonodynamic antimicrobial chemotherapy: First steps towards a sound approach for microbe inactivation. $J$ Photochem Photobiol $B$. 2015;150:44-49. doi: 10.1016/j.jphotobiol.2015.05.012.

2. McHale AP, Callan JF, Nomikou N, Fowley C, Callan B. Sonodynamic therapy: Concept, mechanism and application to cancer treatment. Adv Exp Med Biol. 2016;880:429-450. doi: 10.1007/978-3-319-22536-4_22.

3. Rengeng L, Qianyu Z, Yuehong L, Zhongzhong P, Libo L. Sonodynamic therapy, a treatment developing from photodynamic therapy. Photodiagnosis Photodyn Ther. 2017;19:159-166. doi: 10.1016/j.pdpdt.2017.06.003.

4. Shanei A, Akbari-Zadeh H. Investigating the sonodynamicradiosensitivity Effect of gold nanoparticles on HeLa cervical cancer cells. J Korean Med Sci. 2019;34(37):e243. doi: 10.3346/jkms.2019.34.e243.

5. Ventola CL. The antibiotic resistance crisis: part 1: causes and threats. P T. 2015;40(4):277-283.

6. Mai B, Wang X, Liu Q, Zhang K, Wang P. The application of DVDMS as a sensitizing agent for sono-/phototherapy. Front Pharmacol. 2020;11:19. doi: 10.3389/ fphar.2020.00019.

7. Ohmura T, Fukushima T, Shibaguchi H, Yoshizawa S, Inoue $\mathrm{T}$, Kuroki $\mathrm{M}$, et al. Sonodynamic therapy with 5-aminolevulinic acid and focused ultrasound for deep-seated intracranial glioma in rat. Anticancer Res. 2011;31(7):2527-2533.

8. Fan Z, Kumon RE, Deng CX. Mechanisms of microbubblefacilitated sonoporation for drug and gene delivery. Ther Deliv. 2014;5(4):467-486. doi: 10.4155/tde.14.10.

9. Serpe L, Foglietta F, Canaparo R. Nanosonotechnology: the next challenge in cancer sonodynamic therapy. Nanotechnol Rev. 2012;1(2):173-182. doi: 10.1515/ntrev-2011-0009.

10. Moher D, Shamseer L, Clarke M, Ghersi D, Liberati A, Petticrew M, et al. Preferred reporting items for systematic review and meta-analysis protocols (PRISMA-P) 2015 statement. Syst Rev. 2015;4(1):1. doi: 10.1186/2046-40534-1.

11. Ensing GT, Roeder BL, Nelson JL, van Horn JR, van der Mei HC, Busscher HJ, et al. Effect of pulsed ultrasound in combination with gentamicin on bacterial viability in biofilms on bone cements in vivo. J Appl Microbiol. 2005;99(3):443-8. doi: 10.1111/j.1365-2672.2005.02643.x.

12. Dadjour MF, Ogino C, Matsumura S, Nakamura S, Shimizu N. Disinfection of Legionella pneumophila by ultrasonic treatment with $\mathrm{TiO}_{2}$. Water Res. 2006;40(6):1137-42. doi: 10.1016/j.watres.2005.12.047.

13. Tachibana K, Feril LB Jr, Ikeda-Dantsuji Y. Sonodynamic therapy. Ultrasonics. 2008;48(4):253-259. doi: 10.1016/j. ultras.2008.02.003.

14. Drakopoulou S, Terzakis S, Fountoulakis MS, Mantzavinos D, Manios T. Ultrasound-induced inactivation of gramnegative and gram-positive bacteria in secondary treated municipal wastewater. Ultrason Sonochem. 2009;16(5):62934. doi: 10.1016/j.ultsonch.2008.11.011.

15. Rahman MM, Ninomiya K, Ogino C, Shimizu N. Ultrasound-induced membrane lipid peroxidation and cell damage of Escherichia coli in the presence of non-woven $\mathrm{TiO}_{2}$ fabrics. Ultrason Sonochem. 2010;17(4):738-43. doi: 10.1016/j.ultsonch.2009.12.001.

16. Liu B, Wang DJ, Liu BM, Wang X, He LL, Wang J, et al. The influence of ultrasound on the fluoroquinolones antibacterial activity. Ultrason Sonochem. 2011;18(5):10521056. doi: 10.1016/j.ultsonch.2011.02.001.

17. Nakonechny F, Nisnevitch M, Nitzan Y, Nisnevitch M. Sonodynamic excitation of Rose Bengal for eradication of gram-positive and gram-negative bacteria. Biomed Res Int. 2013;2013:684930. doi: 10.1155/2013/684930.

18. Zhuang D, Hou C, Bi L, Han J, Hao Y, Cao W, et al. Sonodynamic effects of hematoporphyrin monomethyl ether on Staphylococcus aureus in vitro. FEMS Microbiol Lett. 2014;361(2):174-80. doi: 10.1111/1574-6968.12628.

19. Wang X, Ip M, Leung AW, Xu C. Sonodynamic inactivation of methicillin-resistant Staphylococcus aureus in planktonic condition by curcumin under ultrasound sonication. Ultrasonics. 2014;54(8):2109-2114. doi: 
10.1016/j.ultras.2014.06.017.

20. Wang X, Ip M, Leung AW, Yang Z, Wang P, Zhang B, et al. Sonodynamic action of curcumin on foodborne bacteria Bacillus cereus and Escherichia coli. Ultrasonics. 2015;62:75-79. doi: 10.1016/j.ultras.2015.05.003.

21. Wang X, Ip M, Leung AW, Wang P, Zhang H, Hua H, et al. Sonodynamic action of hypocrellin $\mathrm{B}$ on methicillinresistant Staphylococcus aureus. Ultrasonics. 2016;65:13744. doi: 10.1016/j.ultras.2015.10.008.

22. Costley D, Nesbitt H, Ternan N, Dooley J, Huang YY, Hamblin MR, et al. Sonodynamic inactivation of Grampositive and Gram-negative bacteria using a Rose Bengalantimicrobial peptide conjugate. Int J Antimicrob Agents. 2017;49(1):31-36. doi: 10.1016/j.ijantimicag.2016.09.034.

23. Xu F, Hu M, Liu C, Choi SK. Yolk-structured multifunctional up-conversion nanoparticles for synergistic photodynamicsonodynamic antibacterial resistance therapy. Biomater Sci. 2017;5(4):678-685. doi: 10.1039/c7bm00030h.

24. Pang X, Xiao Q, Cheng Y, Ren E, Lian L, Zhang Y, et al. Bacteria-responsive nanoliposomes as smart sonotheranostics for multidrug resistant bacterial infections. ACS Nano. 2019;13(2):2427-2438. doi: 10.1021/ acsnano.8b09336.

25. Moher D, Hopewell S, Schulz KF, Montori V, Gøtzsche PC, Devereaux PJ, et al. CONSORT 2010 explanation and elaboration: updated guidelines for reporting parallel group randomised trials. Int J Surg. 2012;10(1):28-55. doi: 10.1016/j.ijsu.2011.10.001.

26. Bailey MR, Khokhlova VA, Sapozhnikov OA, Kargl SG, Crum LA. Physical mechanisms of the therapeutic effect of ultrasound (A review). Acoust Phys. 2003;49:369-88. doi: 10.1134/1.1591291.

27. Rosenthal I, Sostaric JZ, Riesz P. Sonodynamic therapy-A review of the synergistic effects of drugs and ultrasound. Ultrason Sonochem. 2004;11(6):349-363. doi: 10.1016/j. ultsonch.2004.03.004.

28. Suzuki N, Okada K, Chida S, Komori C, Shimada Y, Suzuki T. Antitumor effect of acridine orange under ultrasonic irradiation in vitro. Anticancer Res. 2007;27(6B):4179-4184.

29. Yumita N, Han QS, Kitazumi I, Umemura S. Sonodynamically-induced apoptosis, necrosis, and active oxygen generation by mono-l-aspartyl chlorin e6. Cancer Sci. 2008;99(1):166-172. doi: 10.1111/j.13497006.2007.00653.x.

30. Tachibana K, Uchida T, Tamura K, Eguchi H, Yamashita $\mathrm{N}$, Ogawa K. Enhanced cytotoxic effect of Ara-C by low intensity ultrasound to HL-60 cells. Cancer Lett. 2000;149(12):189-194. doi: 10.1016/s0304-3835(99)00358-4.

31. Meng L, Liu X, Wang Y, Zhang W, Zhou W, Cai F, et al. Sonoporation of cells by a parallel stable cavitation microbubble array. Adv Sci (Weinh). 2019;6(17):1900557. doi: 10.1002/advs.201900557. 